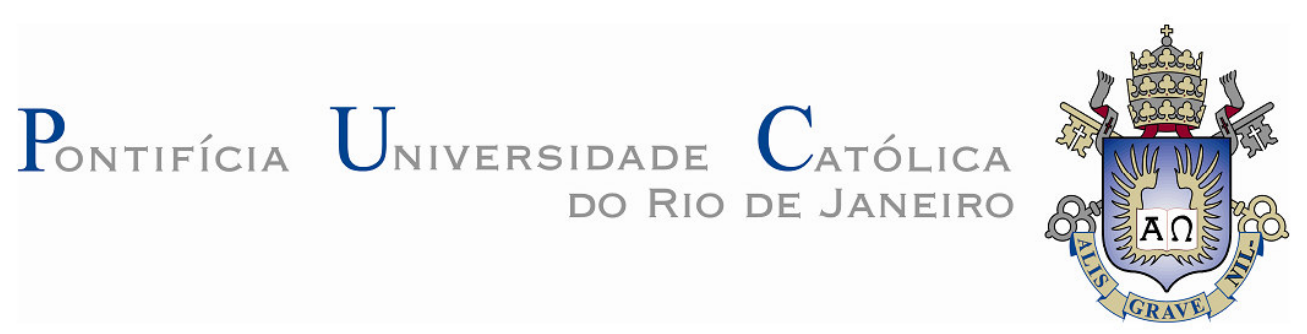

Gerson Alves Bastos

\begin{abstract}
Comportamento Mecânico de Misturas Asfálticas Reforçadas com Geogrelhas para Pavimentos Flexíveis
\end{abstract}

Dissertação de Mestrado

Dissertação apresentada ao Programa de Pós-Graduação em Engenharia Civil da PUC-Rio como requesito parcial para obtenção do título de Mestre em Engenharia Civil.

Orientadora: Michéle Dal Toé Casagrande Co-orientadora: Laura Maria Goretti da Motta

Rio de Janeiro, abril de 2010 


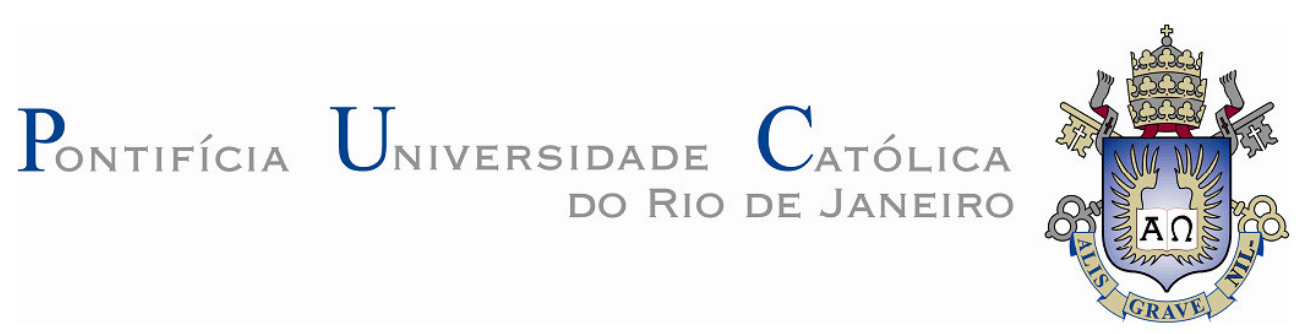

Gerson Alves Bastos

\section{Comportamento Mecânico de Misturas Asfálticas Reforçadas com Geogrelhas para Pavimentos Flexíveis}

Dissertação apresentada como requisito parcial para obtenção do titulo de Mestre pelo Programa de PósGraduação em Engenharia Civil da PUC-Rio. Aprovada pela Comissão Examinadora abaixo assinada.

Michéle Dal Toé Casagrande Orientadora Departamento de Engenharia Civil - PUC-Rio

Laura Maria Goretti da Motta Co-orientadora UFRJ/COPPE

Ben-Hur de Albuquerque e Silva IME/RJ

Alberto de Sampaio Ferraz Jardim Sayão Departamento de Engenharia Civil - PUC-Rio

Anna Laura Lopes da Silva Nunes UFRJ/COPPE

José Eugênio Leal Coordenador Setorial do Centro Técnico Científico - PUC-Rio 
Todos os direitos reservados. É proibida a reprodução total ou parcial do trabalho sem autorização da universidade, do autor e da orientadora.

\section{Gerson Alves Bastos}

Graduou-se em Engenharia Civil pela Universidade de Feira de Santana (UEFS), em 2007, iniciando o curso de mestrado em Engenharia Civil na Pontifícia Universidade Católica do Rio de Janeiro (PUC-Rio) em 2008, desenvolvendo Dissertação na linha de pesquisa de Geotecnia Experimental aplicada a pavimentos.

Ficha Catalográfica

Bastos, Gerson Alves

Comportamento mecânico de misturas asfálticas reforçadas com geogrelhas para pavimentos flexíveis / Gerson Alves Bastos; orientadora: Michéle Dal Toé Casagrande; co-orientadora: Laura Maria Goretti da Motta. -2010.

247 f. : il. (color.) ; $30 \mathrm{~cm}$

Dissertação (mestrado)-Pontifícia Universidade Católica do Rio de Janeiro, Departamento de Engenharia Civil, 2010.

Inclui bibliografia

1. Engenharia civil - Teses. 2. Misturas asfálticas. 3. Pavimentos reforçados. 4. Geossintéticos. 5. Geogrelhas. 6. Ensaios mecânicos. 7. Módulo resiliente. 8. Fadiga. I. Casagrande, Michéle Dal Toé. II. Motta, Laura Maria Goretti da. III. Pontifícia Universidade Católica do Rio de Janeiro. Departamento de Engenharia Civil. IV. Título.

CDD: 624 
Dedico esta Dissertação a meus pais Gerson Oliveira Bastos e Lícia Luiza Alves Bastos 


\section{Agradecimentos}

Devo aqui expressar minha gratidão àqueles que me ajudaram e foram meu apoio nos momentos em que vivi esta dissertação.

DEUS, pois do Senhor viemos e ao Senhor voltaremos.

Aos meus pais, que sempre me incentivaram a fazer a Pós-Gradução.

Ao meu pai, exemplo de tudo que uma pessoa deve ser na vida.

À minha mãe, exemplo de tudo que uma pessoa deve ser na vida.

Aos meus irmãos, Fátima e Helder.

Aos meus sobrinhos, Júlia e Henrique.

Aos meus avós.

Aos amigos da PUC-Rio, em especial: Gino Omar (com quem por inúmeras noites e dias passávamos estudando na minha estimada sala 607c), Luis Fernando, Nilthson, Juliana, Phillip, Antônio... Enfim, a todos que viveram comigo esta etapa.

À Pontifícia Universidade Católica do Rio de Janeiro, em especial ao Programa de Pós-Graduação em Engenharia Civil.

A todos os professores do curso de Geotecnia da PUC-Rio, em especial a Alberto Sayão. Aos professores Anna Laura e Ben-Hur, pela preciosa participação na banca examinadora.

Ao amigo Sergio Takeshima.

À Tatiana Kurata, uma pessoa muito especial em minha vida.

À minha tia Luizinha e aos meus primos que moram no Rio de Janeiro.

À Marise Barbosa, por ter muito me ajudado quando precisava.

Aos amigos em Feira de Santana, em especial a Gutemberg.

A todo pessoal do Departamento de Engenharia Civil da PUC-Rio, em especial a Rita de Cássia.

E claro, às minhas queridas orientadoras Michéle Casagrande e Laura Motta, pelos ensinamentos e por todos os momentos em que pudemos viver as dificuldades, que nos tornaram um pouco mais amadurecidos.

Às empresas que cederam os materiais utilizados nesta pesquisa.

E à CAPES, agência financiadora desta pesquisa. 


\section{Resumo}

Bastos, Gerson Alves; Casagrande, Michéle Dal Toé; Motta, Laura Maria Goretti. Comportamento Mecânico de Misturas Asfálticas Reforçadas com Geogrelhas para Pavimentos Flexíveis. Rio de Janeiro, 2010. 247 p. Dissertação de Mestrado - Departamento de Engenharia Civil, Pontifícia Universidade Católica do Rio de Janeiro.

O principal objetivo deste trabalho foi avaliar o comportamento mecânico de misturas asfálticas reforçadas com geogrelhas. Inicialmente foram previstos ensaios a serem executados em um modelo físico de verdadeira grandeza. Entretanto, devido a um comprometimento estrutural localizado num dos componentes deste modelo físico durante a realização dos ensaios, optou-se por interromper a execução destes e então, elaborar um programa experimental de laboratório, que consistia da extração de amostras deste modelo físico de verdadeira grandeza e moldagem de corpos de prova por amassamento através de compactador giratório. Cada conjunto de amostras (extraídas e moldadas) possuía corpos de prova sem ou com reforço, onde foram estudados dois tipos de geogrelha (de fibra de vidro e poliéster). Foram realizados os ensaios de Resistência à Tração por Compressão Diametral, Módulo de Resiliência, Fadiga por compressão diametral sob carga controlada e Tração em Disco Circular com Fenda. Os resultados dos ensaios mostraram que a presença do reforço de geogrelha melhorou o comportamento mecânico das misturas asfálticas, com a tendência de maior resistência à fratura, fato este evidenciado principalmente pelo ensaio de Tração em Disco Circular com Fenda, onde tais corpos de prova não atingiram o critério de finalização do ensaio (redução da carga aplicada a $0,10 \mathrm{kN}$ ). Nos ensaios de fadiga constatou-se que a melhor influência das geogrelhas ocorre para os menores níveis de tensão aplicada, sendo que nesta condição é permitido um maior período para as geogrelhas se deformarem, condição essencial para sua atuação como elemento com a função de atrasar a propagação de trincas. Constatouse uma melhoria significativa nos resultados obtidos com as amostras reforçadas com as grelhas, tendo as amostras com camada de geogrelha de poliéster apresentado os melhores resultados.

\section{Palavras-chave}

Reforço de Pavimentos; Geogrelhas, Ensaios Mecânicos; Ensaio de Tração em Disco Circular com Fenda. 


\section{Abstract}

Bastos, Gerson Alves; Casagrande, Michéle Dal Toe (Advisor); Motta, Laura Maria Goretti (Co-Advisor). Mechanical Behavior of Asphalt Mixtures Reinforced with Geogrid for Flexible Pavements. Rio de Janeiro, 2010. 247 p. MSC. Dissertation - Departamento de Engenharia Civil, Pontifícia Universidade Católica do Rio de Janeiro.

The objective of this study was to evaluate the mechanical behavior of geogrid reinforced asphalt mixtures. Initially tests were planned to be executed on a physical model, however, this tests had to be stopped due to structural problems. Samples were extracted from the physical model and samples were shaped through gyratory compaction, both for analyze the mechanical laboratory tests. Tensile Resistance (Brazilian Test), Resilient Modulus, Fatigue (controlled load) and Disk-Shaped Compact Tension Geometry Tests were carried out in extracted and shaped samples, without reinforcement and with the reinforcement of two geogrid types (fiberglass and polyester). The reinforcement improved the mechanical behavior of asphalt mixtures, with the trend of greater resistance to fracture, and this was evidenced by Disk-Shaped Compact Tension Geometry Tests, where the final criterion of the test was not reached (reduction of the applied load of $0.10 \mathrm{kN}$ ). The influence of geogrid is better for lower applied stress levels according with the Fatigue Tests. This condition allows the geogrid to deform for a long period, witch is essential for the performance as an element for delay crack propagation. There was a significant improvement in the results obtained with the reinforced samples, for both geogrids studied, but the polyester geogrid reached better results when compared to fiberglass geogrid.

\section{Keywords}

Reinforced Pavements; Geogrids, Mechanical Tests; Disk-Shaped Compact Tension Geometry Test. 


\section{Sumário}

1 Introdução 25

1.1. Objetivos 27

1.2. Estrutura da Dissertação 28

2 Revisão Bibliográfica $\quad 30$

2.1. Ruptura de Pavimentos Asfálticos 30

2.1.1. Fadiga 31

2.2. Trincas em Pavimentos Asfálticos 51

2.2.1. Origens 52

2.2.2. Tipos de Trincamento 57

2.2.3. Trincamento por Reflexão (Mecanismo) 60

2.3. Mecânica da Fratura 66

2.4. Métodos de Combate à Reflexão de Trincas em Pavimentos 71

2.4.1. Camadas de Reforço de Pavimentos Flexíveis 71

2.4.1.1. Recapeamento Convencional 71

2.4.1.2. Materiais com Característica Inibidora ou Retardadora de 72 Trincas

2.4.1.2.1. Revestimento Asfáltico com Uso de Ligantes Modificados 73

2.4.1.2.2. Camadas Intermediárias 77

2.5. Geossintéticos como Camada de Reforço de Pavimentos 80

2.5.1. Histórico 80

2.5.2. Tipos de Geossintéticos $\quad 85$

2.5.3. Utilização de Geogrelhas em Pavimentos 87

2.6. Considerações sobre o Ensaio de Tração em Disco Circular 97 com Fenda

$\begin{array}{ll}\text { 2.7. Considerações Finais } & 102\end{array}$

3 Programa Experimental 103

3.1. Considerações Iniciais 103 
3.2. Tanque-Teste de Pavimentos 104

3.2.1. Características do Tanque-Teste de Pavimentos 106

3.2.2. Estrutura do Pavimento Experimental no Tanque-Teste 111

3.2.3. Seções de Ensaios no Pavimento Experimental Reforçado 121 com Geogrelhas

3.2.4. Ensaios no Pavimento Experimental 127

3.3. Metodologia 128

3.3.1. Ensaios no Tanque-Teste e Extração de Corpos-de-Prova $\quad 130$

3.3.1.1. Flexão 131

3.3.1.2. Cisalhamento 135

3.3.1.3. Extração de Corpos-de-Prova do Tanque-Teste 137

3.3.2. Moldagem dos Corpos-de-Prova em Laboratório 139

3.3.3. Ensaios Mecânicos 147

3.3.3.1. Ensaio de Módulo de Resiliência por Compressão 147 Diametral

3.3.3.2. Resistência à Tração por Compressão Diametral 149

3.3.3.3. Ensaio de Fadiga por Compressão Diametral 150

3.3.3.4. Ensaio de Tração em Disco Circular com Fenda 151

3.4. Considerações Finais 160

4 Apresentação e Análises dos Resultados 161

4.1. Ensaios Dinâmicos no Tanque-Teste 161

4.2. Ensaios Mecânicos nos Corpos-de-Prova 165

4.2.1. Corpos-de-Prova Extraídos do Tanque-Teste 167

4.2.2. Corpos-de-Prova Moldados em Laboratório 178

4.3. Comparativo entre os Resultados dos Ensaios 191

4.4. Correlações entre os Parâmetros do Ensaio de Tração em 207 Disco Circular com Fenda $(\operatorname{Dc}(\mathrm{T}))$ e Resistência à Tração Estática (Rt)

4.5 Considerações Finais 210

5 Conclusões e Recomendações 212

5.1. Conclusões 212 
5.2. Recomendações

6 Referências Bibliográficas

ANEXO A

ANEXO B 


\section{Lista de Figuras}

Figura 2.1: Tensões no interior de um pavimento 37

Figura 2.2: Limite de Fadiga (curva S-N) 39

Figura 2.3: Representação esquemática da fratura por fadiga 42

Figura 2.4: Propagação de trincas em mistura asfáltica $\quad 57$

Figura 2.5: Distribuição de tensões na extremidade da trinca 57

Figura 2.6: Trinca de fadiga de baixo nível de severidade $\quad 59$

Figura 2.7: Trinca de fadiga de médio nível de severidade $\quad 60$

Figura 2.8: Trincas de fadiga (tipo "couro-de-jacaré") de alto nível de severidade 60

Figura 2.9: Movimentações possíveis de uma trinca 66

Figura 2.10: Comparação entre a Mecânica dos Meios Contínuos e a Mecânica da Fratura 67

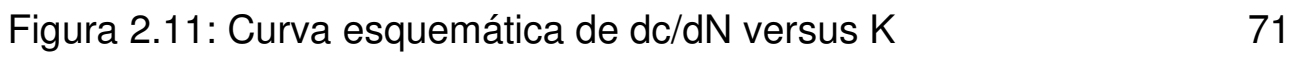

Figura 2.12: Comparação entre diferentes geometrias de corpos de $\begin{array}{ll}\text { prova para ensaio de fratura } & 101\end{array}$

Figura 2.13: Dimensões do corpo de prova para ensaio em Disco Circular com Fenda

Figura 3.1: Planta Baixa do Tanque-Teste de Pavimentos

106

Figura 3.2 - Prédio onde está localizado o Tanque - teste de

Pavimentos

107

Figura 3.3: Piezômetro e Tubulação para abastecimento de água no interior do tanque

Figura 3.4: Planta Baixa do Tanque-Teste de Pavimentos (medidas em metros)

Figura 3.5: Esquema do posicionamento de alguns dos componentes do Tanque-Teste de Pavimentos (TDRs, células de carga e camada de brita) no interior da estrutura

Figura 3.6: Cilindro aplicador de cargas e LVDTs no tanque-teste

Figura 3.7: Sistema de aquisição de dados e células de carga utilizadas no Tanque - Teste

Figura 3.8: Esquema das camadas do pavimento experimental 
Figura 3.9: Curva de Vida de Fadiga em função da diferença de tensões da mistura asfáltica

Figura 3.10: Curva de Vida de Fadiga em função da deformação específica resiliente da mistura asfáltica

Figura 3.11: Configuração esquemática do Tanque-Teste após execução das seções-teste e das trincas artificiais, e locais em que foi feito poços e extraído corpos-de-prova

Figura 3.12: Configuração das três seções-teste e das trincas produzidas de modo artificial

Figura 3.13: Locais em que foram extraídos materiais do pavimento experimental

Figura 3.14: Projeção dos cortes delimitando as seções-teste e das trincas artificiais

Figura 3.15: Aspecto da geogrelha de fibra de vidro usada neste estudo

Figura 3.16: Geogrelhas de poliéster (revestida com betume) e de fibra de vidro usadas neste estudo, dispostas lado a lado

Figura 3.17: Passos da montagem do experimento no Tanque teste

Figura 3.18: Cilindros de carga utilizados nesta pesquisa (êmbolo: $160 \mathrm{~mm}$ e $200 \mathrm{~mm}$ )

Figura 3.19: Fluxograma das etapas previstas para realização desta pesquisa

Figura 3.20: Configuração do primeiro ensaio para etapa de flexão Seção teste 1

Figura 3.21: Local do ensaio (FL1) em que foi observada apenas ruptura localizada do revestimento asfáltico

Figura 3.22: Calibração do novo cilindro de carga no tanque - teste neste estudo

Figura 3.23: Comparação entre os perfis metálicos: inicialmente disponível e atual

Figura 3.24: Representação esquemática da atual configuração da placa de carregamento 
Figura 3.25: Ensaio por cisalhamento com a placa metálica retangular (área de $450 \mathrm{~cm}^{2}$ ) 137

Figura 3.26: Extração de corpos-de-prova do tanque-teste 139

Figura 3.27: Corpos de prova extraídos e faceados: a) seção-teste sem geogrelha; b) seção-teste de geogrelha de fibra de vidro e c) seção-teste de geogrelha de poliéster

Figura 3.28: Gráfico Viscosidade versus Temperatura do ligante REPLAN

Figura 3.29: Compactador Giratório para moldagem de corpos-deprova do Laboratório de Pavimentos da COPPE/UFRJ 145

Figura 3.30: Aplicação de emulsão asfáltica na primeira metade do corpo-de-prova moldado

Figura 3.31: Colocação da camada intermediária (no caso apenas como ilustração, é mostrada a geogrelha de fibra de vidro utilizada) 146

Figura 3.32: Reaplicação de emulsão asfáltica sobre a geogrelha 146 Figura 3.33: Corpo de prova após conclusão da compactação neste estudo

Figura 3.34: Corpos de prova após moldagem em laboratório

Figura 3.35: Equipamento e execução de ensaio de Módulo de Resiliência na COPPE

Figura 3.36: Equipamento e ensaio de Resistência à tração estática

Figura 3.37: Esquema do Ensaio de Fadiga por compressão diametral

152

Figura 3.38: Execução dos furos de carregamento nos corpos de prova

Figura 3.39: Execução da pré-trinca e do chanfro nos corpos de prova para ensaio de tração 155

Figura 3.40: Corpos de prova moldados com pintura branca na provável região de propagação da trinca

Figura 3.41: Dimensões das placas de alumínio utilizadas para acoplagem do clip-on-gage

Figura 3.42: Câmara de condicionamento de temperatura das amostras utilizadas 
Figura 3.43: Corpo de prova com termopar para controle de temperatura, dentro da câmara de condicionamento $(\mathrm{HIRSCH}, 2009) 158$ Figura 3.44: Garras utilizadas para fixação do corpo-de-prova na prensa de carregamento do ensaio 159

Figura 3.45: Prensa utilizada para realização dos ensaios no Laboratório de Estruturas da COPPE/UFRJ 159

Figura 3.46: Clip - on - gage empregado nos ensaios de tração neste estudo

Figura 3.47: Configuração final para o início do ensaio de tração em disco com fenda (garras de carregamento, corpo-de-prova e clip-ongage)

Figura 4.1: Deslocamento plástico (no local referente à trinca FL3) em função do número de golpes aplicados

Figura 4.2: Deslocamento elástico (no local referente à trinca FL3) em função do número de golpes aplicados

Figura 4.3: Deslocamento plástico no local referente à trinca C3 em função do número de golpes aplicados

Figura 4.4: Deslocamento elástico no local referente à trinca C3 em função do número de golpes aplicados 165

Figura 4.5: Tela principal do software TRAPEZIUM X (HIRSCH, 2009)

Figura 4.6: Gráfico Carga versus Abertura da trinca para os corposde-prova extraídos da Seção-Teste 1

Figura 4.7: Corpo-de-prova cuja fratura ocorreu através de um dos furos de carregamento

Figura 4.8: Gráfico Carga versus Abertura da trinca para os corposde-prova extraídos da Seção-Teste 2

Figura 4.9: Gráfico Carga versus Abertura da trinca para os corposde-prova extraídos da Seção-Teste 3

Figura 4.10: Gráfico de Vida de Fadiga (número de golpes versus diferença de tensões) para os corpos-de-prova moldados sem presença de camada intermediária de geogrelha 182

Figura 4.11: Gráfico de Vida de Fadiga (número de golpes versus 
deformação específica resiliente) para os corpos-de-prova moldados sem presença de camada intermediária de geogrelha

Figura 4.12: Corpo-de-prova sem geogrelha (SG 13904) com ruptura no furo de carregamento

Figura 4.13: Gráfico Carga versus Abertura da trinca para o corpode-prova (SG 13921)

Figura 4.14: Gráfico de Vida de Fadiga (número de golpes versus diferença de tensões) para os corpos-de-prova moldados com a presença de camada intermediária de geogrelha de fibra de vidro

Figura 4.15: Gráfico de Vida de Fadiga (número de golpes versus deformação específica resiliente) para os corpos-de-prova moldados com a presença de camada intermediária de geogrelha de fibra de vidro

Figura 4.16: Gráfico Carga versus Abertura da trinca para o corpode-prova FV 13891

Figura 4.17: Gráfico de Vida de Fadiga (número de golpes versus diferença de tensões) para os corpos-de-prova moldados com a presença de camada intermediária de geogrelha de poliéster

Figura 4.18: Gráfico de Vida de Fadiga (número de golpes versus deformação específica resiliente) para os corpos-de-prova moldados com a presença de camada intermediária de geogrelha de poliéster

Figura 4.19: Corpo-de-prova (HT 13867) com camada intermediária de geogrelha de poliéster cuja ruptura ocorreu em um dos furos de carregamento

Figura 4.20: Gráfico Carga versus Abertura da trinca para o corpode-prova $(\mathrm{HT})$

Figura 4.21: Valores médios de Resistência à Tração Estática (SG: sem geogrelha; FV: geogrelha de fibra de vidro e HT: geogrelha de poliéster) das amostras deste estudo

Figura 4.22: Valores médios de Módulo de Resiliência das amostras deste estudo

Figura 4.23: Relação entre Módulo de Resiliência (MR) e Resistência à Tração (RT) para os corpos-de-prova extraídos 
Figura 4.24: Valores médios de energia de fratura para os corpos-deprova ensaiados (DC(T))

Figura 4.25: Valores médios da carga máxima dos corpos-de-prova ensaiados (DC $(\mathrm{T}))$

Figura 4.26: Correlação entre MR/RT e Energia de fratura para os corpos-de-prova ensaiados

Figura 4.27: Valores médios recalculados de energia de fratura para os corpos-de-prova ensaiados (DC(T)), excluindo-se os corpos-deprova de valores discrepantes

Figura 4.28: Valores médios recalculados da carga máxima dos corpos-de-prova ensaiados (DC(T)), excluindo-se os corpos-deprova de valores discrepantes

Figura 4.29: Correlação entre MR/RT e Energia de fratura para os corpos-de-prova ensaiados, excluindo-se os corpos-de-prova de valores discrepantes

Figura 4.30: Valores médios de Resistência à Tração Estática (SG: sem geogrelha; FV: geogrelha de fibra de vidro e HT: geogrelha de poliéster)

Figura 4.31: Valores médios de Módulo de Resiliência para os corpos de prova moldados no compactador giratório

Figura 4.32: Relação entre Módulo de Resiliência (MR) e Resistência à Tração $(R T)$ para os corpos-de-prova moldados

Figura 4.33: Curvas de fadiga para os corpos-de-prova (sem geogrelha, geogrelha de fibra de vidro e de poliéster)

Figura 4.34: Exemplo de corpos-de-prova rompido ao final do ensaio de fadiga: a) corpos-de-prova com presença de geogrelha e b) corpo-de-prova sem camada de geogrelha

Figura 4.35: Valores médios de energia de fratura para os corpos-deprova ensaiados (DC(T))

Figura 4.36: Valores médios da carga máxima dos corpos-de-prova ensaiados $(\mathrm{DC}(\mathrm{T}))$

Figura 4.37: Correlação entre MR/RT e Energia de fratura para os corpos-de-prova ensaiados 
Figura 4.38: Correlação entre RT e Gf para os corpos-de-prova extraídos sem geogrelha (SG), com geogrelha de fibra de vidro (FV) e geogrelha de poliéster $(\mathrm{HT})$, além dos corpos-de-prova obtidos de HIRSCH (2009)

Figura 4.39: Correlação entre RT e Gf para os corpos-de-prova moldados sem geogrelha (SG), com geogrelha de fibra de vidro (FV) e geogrelha de poliéster (HT), além dos corpos-de-prova obtidos de HIRSCH (2009)

Figura 4.40: Corpo de prova rompido após ensaio de tração em disco circular com fenda

Figura A.1: Ensaio DC(T) - corpo-de-prova sem presença de reforço de geogrelha (CP 13971)

Figura A.2: Ensaio $\mathrm{DC}(\mathrm{T})$ - corpo-de-prova sem presença de reforço de geogrelha (CP 13972)

Figura A.3: Ensaio DC(T) - corpo-de-prova sem presença de reforço de geogrelha (CP 13973)

Figura A.4: Ensaio DC(T) - corpo-de-prova sem presença de reforço de geogrelha (CP 13975)

Figura A.5: Ensaio DC(T) - corpo-de-prova com reforço de geogrelha de fibra de vidro (CP 13982)

Figura A.6: Ensaio DC(T) - corpo-de-prova com reforço de geogrelha de fibra de vidro (CP 13985)

Figura A.7: Ensaio DC(T) - corpo-de-prova com reforço de geogrelha de fibra de vidro (CP 13986)

Figura A.8: Ensaio DC(T) - corpo-de-prova com reforço de geogrelha de fibra de vidro (CP 13987)

Figura A.9: Ensaio DC(T) - corpo-de-prova com reforço de geogrelha de fibra de vidro (CP 13990)

Figura A.10: Ensaio DC(T) - corpo-de-prova com reforço de geogrelha de poliéster (CP 13998)

Figura A.11: Ensaio DC(T) - corpo-de-prova com reforço de geogrelha de poliéster (CP 14001)

Figura A.12: Ensaio DC(T) - corpo-de-prova com reforço de 
geogrelha de poliéster (CP 14002)

Figura A.13: Ensaio DC(T) - corpo-de-prova com reforço de geogrelha de poliéster (CP 14004)

Figura A.14: Ensaio DC(T) - corpo-de-prova com reforço de geogrelha de poliéster (CP 14008)

Figura B.1: Ensaio DC(T) - corpo-de-prova sem reforço de geogrelha (CP 13921)

Figura B.2: Ensaio DC(T) - corpo-de-prova com reforço de geogrelha de fibra de vidro (CP 13891)

Figura B.3: Ensaio DC(T) - corpo-de-prova com reforço de geogrelha de poliéster (CP 13865) 


\section{Lista de Tabelas}

Tabela 2.1: Comparação entre diferentes geometrias de corpos-deprova para ensaio de fratura

Tabela 3.1: Características do ligante e mistura asfáltica do revestimento "antigo"

Tabela 3.2: Características do equipamento compactador manual

Tabela 3.3: Caracterização dos agregados da mistura asfáltica compactada nesta dissertação

Tabela 3.4: Características do ligante utilizado na mistura asfáltica compactada

Tabela 3.5: Granulometria da mistura do revestimento novo (proporção dos agregados)

Tabela 3.6: Características da mistura asfáltica compactada

Tabela 3.7: Características da mistura asfáltica empregada no

Tanque-Teste

Tabela 3.8: Resistência à Tração e Módulo de Resiliência da mistura asfáltica deste estudo

Tabela 3.9: Valores de tensões a diferentes profundidades, obtidos pelo ELSYM5, sob o centro do carregamento para o tanque - teste na configuração original

Tabela 3.10: Característica do ligante - CAP 50/70

Tabela 3.11: Granulometria dos agregados usados na moldagem dos cps desta pesquisa

Tabela 3.12: Propriedades dos agregados

Tabela 3.13: Temperaturas de mistura, de compactação, dos agregados e do ligante

Tabela 3.14: Planejamento experimental dos ensaios mecânicos nos corpos-de-prova

Tabela 4.1: Valores de parâmetros volumétricos para os corpos-deprova extraídos da seção-teste 1 desta pesquisa 
Resiliência dos corpos-de-prova extraídos da Seção-Teste 1 desta pesquisa

Tabela 4.3: Resultados do ensaio de Tração em Disco Circular com Fenda $(\mathrm{DC}(\mathrm{T}))$ realizados nos corpos-de-prova da Seção-Teste 1

Tabela 4.4: Valores de massa específica aparente e volume de vazios para os corpos-de-prova extraídos da seção-teste 2

Tabela 4.5: Valores da Resistência à Tração e do Módulo de Resiliência dos corpos-de-prova extraídos da Seção-Teste 2

Tabela 4.6: Resultados do ensaio de Tração em Disco Circular com Fenda (DC(T)) realizados nos corpos-de-prova da Seção-Teste 2

Tabela 4.7: Valores de massa específica aparente e volume de vazios dos corpos-de-prova da seção-teste 3

Tabela 4.8: Valores da Resistência à Tração e do Módulo de Resiliência dos corpos-de-prova extraídos da Seção-Teste 3 Tabela 4.9: Resultados do ensaio de Tração em Disco Circular com Fenda (DC(T)) realizados nos corpos-de-prova da Seção-Teste 3 Tabela 4.10: Valores de parâmetros volumétricos para os corpos-deprova moldados sem geogrelha

Tabela 4.11: Valores da Resistência à Tração e do Módulo de Resiliência dos corpos-de-prova moldados sem geogrelha

Tabela 4.12: Resultado do ensaio de Tração em Disco Circular com Fenda $(\mathrm{DC}(\mathrm{T}))$ realizado no corpo-de-prova sem camada de geogrelha moldado em laboratório

Tabela 4.13: Valores de parâmetros volumétricos para os corpos-deprova moldados com geogrelha de fibra de vidro

Tabela 4.14: Valores da Resistência à Tração e do Módulo de Resiliência dos corpos-de-prova moldados com geogrelha de fibra de vidro

Tabela 4.15: Resultado do ensaio de Tração em Disco Circular com Fenda $(\mathrm{DC}(\mathrm{T}))$ realizado no corpo-de-prova com camada de geogrelha moldado em laboratório

Tabela 4.16: Valores de parâmetros volumétricos para os corpos-deprova moldados com geogrelha de poliéster 
Tabela 4.17: Valores da Resistência à Tração e do Módulo de Resiliência dos corpos-de-prova moldados com geogrelha de poliéster

Tabela 4.18: Resultado do ensaio de Tração em Disco Circular com Fenda $(\mathrm{DC}(\mathrm{T})$ ) realizado no corpo-de-prova com camada de geogrelha moldado em laboratório

Tabela 4.19: Valores dos parâmetros dos ensaios de fadiga e tração em disco circular com fenda $(\mathrm{DC}(\mathrm{T}))$ para as amostras moldadas pelo compactador giratório

Tabela 4.20: Resultados de Resistência à Tração e Energia de Fratura (HIRSCH, 2009)

Tabela 4.21: Resultados de Resistência à Tração e Energia de Fratura para os corpos-de-prova extraídos 209

Tabela 4.22: Resultados de Resistência à Tração e Energia de 210 Fratura para os corpos-de-prova moldados 


\section{Lista de Abreviaturas}

AASHTO = American Association of State Highway and Transportation Officials

$\begin{array}{ll}\text { ABNT } & =\text { Associação Brasileira de Normas Técnicas } \\ \text { ANIP } & =\text { Associação Nacional da Indústria de Pneumáticos } \\ \text { ASTM } & =\text { American Society for Testing and Materials } \\ \text { CA } & =\text { Concreto Asfáltico } \\ \text { CAP } & =\text { Cimento Asfáltico de Petróleo } \\ \text { CBUQ } & =\text { Concreto Betuminoso Usinado a Quente } \\ \text { CP } & =\text { Corpo de Prova } \\ \text { DNER } & =\text { Departamento Nacional de Estradas de Rodagem } \\ \text { DNIT } & =\text { Departamento Nacional de Infraestrutura de } \\ \text { FEG } & \text { Transportes } \\ \text { HRB } & =\text { Fator de Eficiência do Geossintético } \\ \text { ISC } & =\text { Índice de Suporte Califórnia } \\ \text { LVDT } & =\text { Linear Variable Differential Transformer } \\ \text { MR } & =\text { Módulo de Resiliência } \\ \text { RT } & =\text { Resistência à Tração } \\ \text { SUCS } & =\text { Sistema Unificado de Classificação dos Solos } \\ \text { TDR } & =\text { Time-Domain Reflectometer } \\ \text { WASHO } & =\text { Western Association of State Highway Officials }\end{array}$




\section{Lista de Símbolos e Siglas}

\begin{tabular}{|c|c|}
\hline$v$ & = coeficiente de Poisson \\
\hline$\Delta \sigma$ & = diferença de tensões \\
\hline$\sigma_{3}$ & $=$ tensão de confinamento \\
\hline$\sigma_{\mathrm{d}}$ & = tensão desviadora \\
\hline$\varepsilon_{\mathrm{r}}$ & = deformação específica resiliente \\
\hline $\mathrm{C} 1, \mathrm{C} 2, \mathrm{C} 3$ & $\begin{array}{l}\text { = trincas que correspondiam aos locais em que deveriam ser } \\
\text { executados ensaios por modo de carregamento a } \\
\text { cisalhamento }\end{array}$ \\
\hline Dap & = densidade aparente \\
\hline $\mathrm{DC}(\mathrm{T})$ & = ensaio de Tração em Disco Circular com Fenda \\
\hline DMM & = densidade máxima medida \\
\hline Dt & = densidade teórica \\
\hline FL1, FL2, F & $\begin{array}{l}3 \text { = trincas que correspondiam aos locais em que } \\
\text { deveriam ser executados ensaios por modo de } \\
\text { carregamento à flexão }\end{array}$ \\
\hline FV & $\begin{array}{l}\text { = indica amostras com camada intermediária de geogrelha } \\
\text { de fibra de vidro }\end{array}$ \\
\hline $\mathrm{G}_{f}$ & $=$ energia de fratura \\
\hline Gmb & $\begin{array}{l}=\text { massa específica aparente de mistura asfáltica } \\
\text { compactada }\end{array}$ \\
\hline Gmm & = massa específica máxima medida \\
\hline GW & $=$ Pedregulhos bem graduados, com pouco ou nenhum fino \\
\hline HT & $\begin{array}{l}=\text { indica amostras com camada intermediária de geogrelha } \\
\text { de poliéster }\end{array}$ \\
\hline $\mathrm{K}, \mathrm{n}$ & $\begin{array}{l}=\text { constantes resultantes de regressão linear (em ensaio de } \\
\text { fadiga) }\end{array}$ \\
\hline $\mathrm{K}_{\mathrm{I}}, \mathrm{K}_{\mathrm{II}}, \mathrm{K}_{\mathrm{III}}$ & $=$ fatores de intensidade de tensões \\
\hline $\mathrm{N}$ & = Número de operações do eixo padrão rodoviário \\
\hline \multicolumn{2}{|c|}{$\mathrm{RBV}=$ relação betume/vazios } \\
\hline SG & de \\
\hline
\end{tabular}




$\begin{array}{ll}\text { SW } & =\text { Areias bem graduada, pedregulhosas, e com poucos finos } \\ \text { VAM } & =\text { vazios do agregado mineral } \\ \text { VCB } & =\text { vazios com betume } \\ V_{V} & =\text { volume de vazios }\end{array}$

